\title{
Ornamental Pepper (Capsicum annuum L.) Cultivars Comprising the Christmas Lights Cultivar Series
}

\author{
John R. Stommel ${ }^{1}$ and Mikhail Kozlov \\ Genetic Improvement of Fruits and Vegetables Laboratory, U.S. Department \\ of Agriculture, Agricultural Research Service, Beltsville Agricultural \\ Research Center, Beltsville, MD 20705-2325
}

\author{
Robert J. Griesbach \\ Floral and Nursery Plant Research Unit, U.S. Department of Agriculture, \\ Agricultural Research Service, U.S. National Arboretum, Beltsville, MD \\ 20705-2325
}

Additional index words. pepper, ornamentals, breeding

Ornamental peppers (Capsicum annuum L.) belong to the plant family Solanaceae, which includes ornamentals such as the Brugmansia (Angel's trumpet), Brunfelsia, Browallia (Bush violet), Datura, Nicotiana, Petunia, and Salpiglossis. Solanum pseudocapsicum (Jerusalem Cherry) and Solanum capsicastrum (False Jerusalem Cherry) are often confused with ornamental pepper.

The genus Capsicum is native to the tropics of Central and South America. Pepper cultivation is ancient in the Americas where they were valued for their culinary and medicinal properties (Pickersgill, 1969a, 1969b). Peppers were introduced to Europe by Columbus, and subsequently to Africa and Asia by the extensive trading routes of the Spanish and Portuguese. When introduced to Europe in the 15th century, peppers were held in higher esteem as an ornamental plant than as a food source. Ornamental peppers as potted or bedding plants and a florist crop are still popular today (Stommel and Bosland, 2005).

Ornamental peppers have been known as "Christmas peppers" for many years in the floriculture industry (Harthun, 1991). Pepper plants with vibrant green foliage and bright red fruits have traditionally been sold during the winter holiday season. Ornamental peppers with their bright contrasting colors and edible fruits were the most popular Christmas gift plant until the 1960s when the poinsettia industry began to introduce and promote improved poinsettia cultivars.

Modern ornamental peppers exhibit considerable diversity in plant habit and morphology.

\footnotetext{
Received for publication 5 Oct. 2017. Accepted for publication 10 Jan. 2018.

Mention of trade names or commercial products is solely for the purpose of providing specific information and does not imply recommendation or endorsement by the United States Department of Agriculture.

1'Corresponding author. E-mail: john.stommel@ ars.usda.gov.
}

Plants range in size and shape from short, compact plants with small fruit, such as 'Holiday Cheer', to plants as tall as three to four feet, with full-sized fruits, such as 'NuMex Mirasol'. This diversity, together with assorted ripe fruit color and varying hues of green to purple to black foliar pigmentation, affords a myriad of opportunities to develop unique ornamental cultivars suitable for use as potted types, bedding and garden plants, and cut stems.

Ornamental peppers grown as potted plants are widely marketed for retail sale in the fall and winter months. Availability of compact plants with colorful fruit, ease of propagation from seed, relatively short cropping time, heat and drought tolerance, and excellent keeping quality are valuable attributes of ornamental peppers for commercial propagators. As bedding and garden plants, heat and drought tolerance and vibrant colors, have made ornamental peppers popular as border or specimen plants, or in mass plantings.

The Agricultural Research Service of the U.S. Department of Agriculture (USDA) announced the release of the ornamental pepper (C. annuum) Christmas Lights cultivar series. The Christmas Lights series comprises four cultivars named Christmas Lights Blue/Red, Christmas Lights Blue/Orange, Christmas Lights Yellow/Red, and Christmas Lights Yellow/Orange. Color designations denote immature/mature fruit color for the respective cultivars. These cultivars are intended for ornamental applications. With their compact growth habit, prolific fruit set, and distinctively shaped fruit with vibrant contrasting colors, the Christmas Lights cultivars are well-suited for bedding plant production and container plant production, during the summer and fall garden and holiday season.

\section{Origin}

The cultivars comprising the Christmas Lights cultivar series are true-breeding selections
(Christmas Lights Blue/Red, $\mathrm{F}_{11}$ generation; Christmas Lights Blue/Orange, $\mathrm{F}_{13}$ generation; Christmas Lights Yellow/Red, $F_{11}$ generation; and Christmas Lights Yellow/ Orange, $F_{12}$ generation) derived from a segregating $\mathrm{F}_{2}$ population. The pedigree is complex and originated from initial crosses between the USDA germplasm release 90C44 (Stommel and Griesbach, 1993) and the heirloom cultivars Christmas Cheer and Royal Black (Fig. 1). Initial crosses also included the sweet bell cultivars Summer Sweet 860 and Ariane. Line 90C44 is truebreeding and has a characteristic compact upright growth habit, black foliage, and upright clusters of tabasco-type fruit that mature from black to red. 'Royal Black' also bears tabasco-type fruit that mature from black to red, but foliage is variegated green/ violet/black and segregates for variegation intensity. Conical fruit shape of the Christmas Lights cultivars is derived from 90C44 and 'Royal Black', but the Christmas Lights cultivars exhibit broader fruit diameter at the calyx and reduced fruit length typical of 'Christmas Cheer'. 'Christmas Cheer' has green foliage and is typified by a very prostrate growth habit and upright oriented 2-3 cm diameter globe-shaped fruit that mature from pale yellow to red. The growth habit of Christmas Lights cultivars is intermediate to that of the upright, yet compact, 90C44 and extremely prostrate habit of 'Christmas Cheer'. Earliness of Christmas Lights cultivars is comparable with 'Christmas Cheer'. 'Summer Sweet 860' and 'Ariane' produce blocky bell-shaped fruit that mature from green to red and orange, respectively.

Early generations focused on selection of lines with pale yellow-colored, anthocyaninfree fruit and lines with anthocyanin pigmented fruit, but reduced fruit chlorophyll concentration, yielding "blue-" or violetcolored fruit. Segregation for mature fruit color permitted selection within respective pale yellow and violet immature fruit populations for red and orange mature fruit color lines. Concurrent selection was practiced for fruit size uniformity and shape and vigorous, yet compact plants that would perform well season-long under bedding plant conditions and be suitable for container production (Figs. 2 and 3). Stringent selection against sweet bell fruit shape attributes was practiced in early generations of the Christmas Lights series. The sweet bell cultivars were also parents in the early generation crosses of pedigrees for the ornamental pepper Lil' Pumpkin $^{\mathrm{TM}}$ (Stommel and Griesbach, 2008) which retained some bell pod type attributes.

The cultivars comprising the Christmas Lights cultivar series were trialed under field conditions in Beltsville, MD (heatzone 7) (American Horticultural Society, 1997) and evaluated in pot culture in Dearing, GA (heat-zone 9). In these trials, growers noted the plant's prolific fruit set and vibrant display of upright fruit with early season "blue" (violet) or pale yellow immature fruit color and mid- to late-season contrasting displays of red or orange mature 


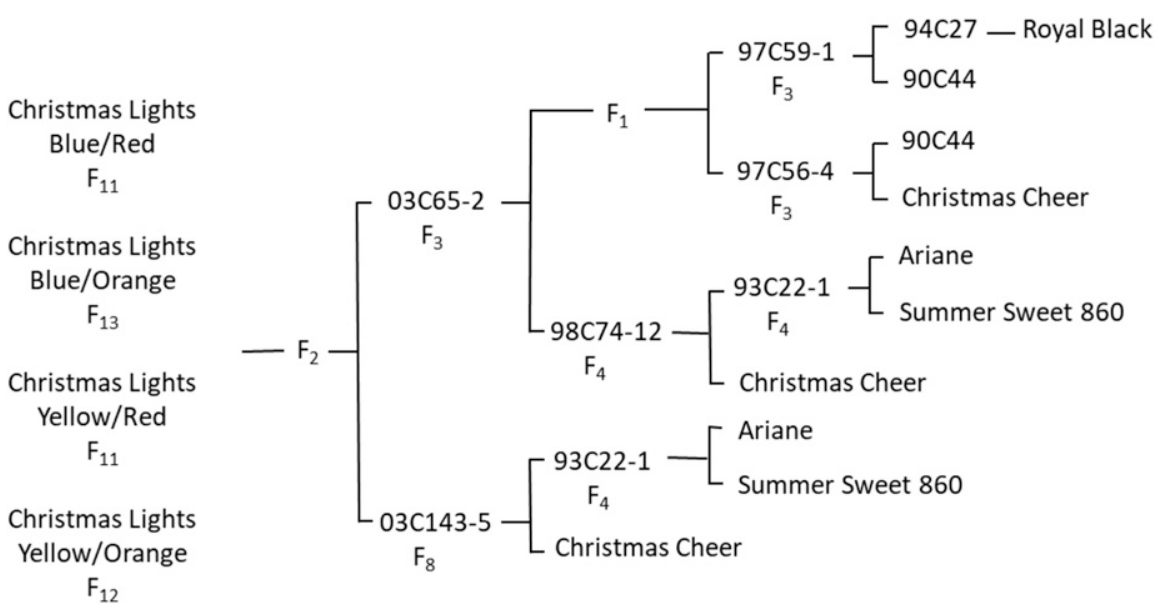

Fig. 1. Pedigree for ornamental pepper (Capsicum annuum L.) cultivars comprising the following Christmas Lights cultivar series: 'Christmas Lights Blue/Red', 'Christmas Lights Blue/Orange', 'Christmas Lights Yellow/Red', and 'Christmas Lights Yellow/Orange'. Color designations for the respective cultivars denote immature fruit color (blue or yellow) and mature fruit color (red or orange).
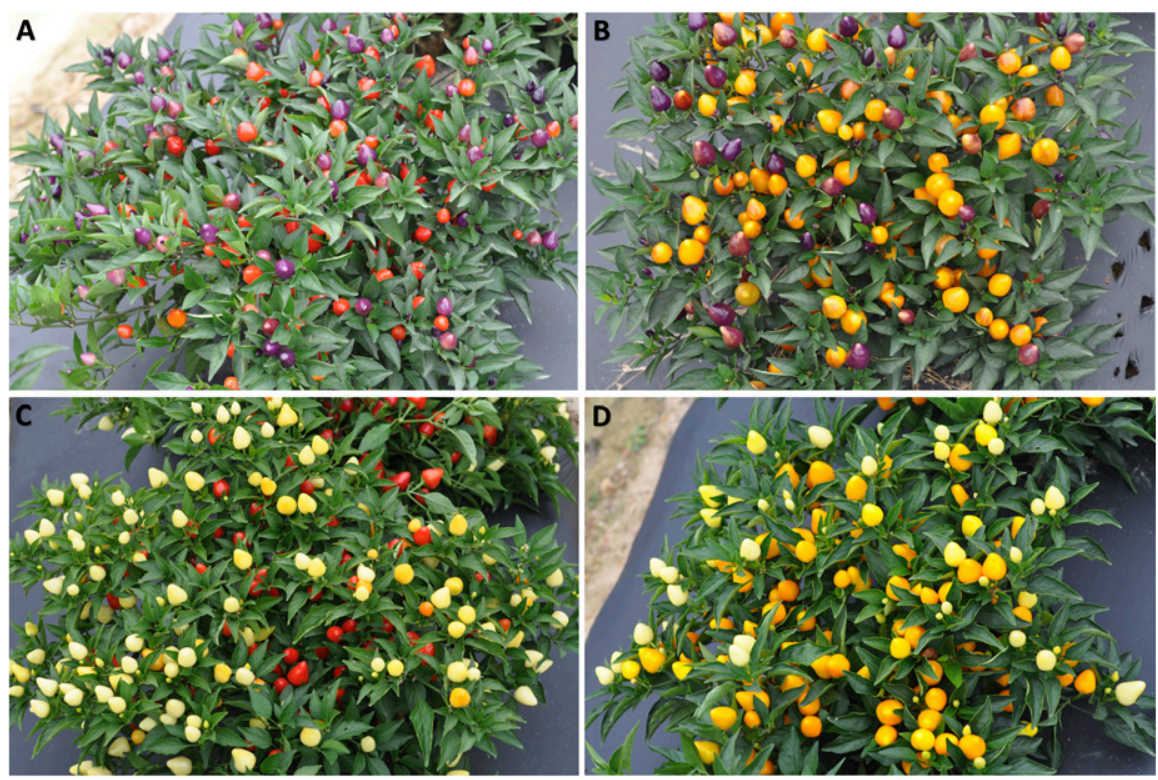

Fig. 2. Whole plant images of the ornamental pepper (Capsicum annuum L.) cultivars comprising the following Christmas Lights cultivar series: (A) 'Christmas Lights Blue/Red'; (B) 'Christmas Lights Blue/Orange'; (C) 'Christmas Lights Yellow/Red'; and (D) 'Christmas Lights Yellow/Orange'. Color designations denote pigmentation of immature and mature fruit, respectively.

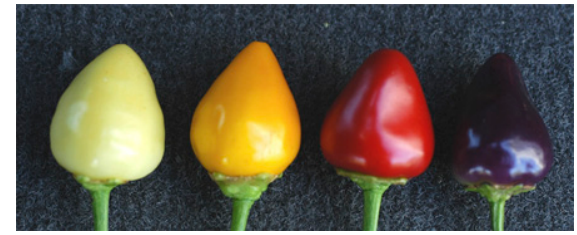

Fig. 3. Close-up fruit images illustrating the characteristic fruit shape and pigmentation for the ornamental pepper (Capsicum annuиm L.) cultivars comprising the following Christmas Lights cultivar series: 'Christmas Lights Blue/ Red', 'Christmas Lights Blue/Orange', 'Christmas Lights Yellow/Red', and 'Christmas Lights Yellow/Orange'. Color designations denote pigmentation of immature and mature fruit, respectively. fruit color. Sequential fruit sets result in mid- and late-season mixed displays of immature and mature fruit for the respective cultivars.

\section{Description}

The Christmas Lights series of cultivars are diploid $(2 n=2 x=24)$ herbaceous annuals. The individual cultivars exhibit uniform morphology and breed true from seed. These cultivars have performed stably in multiple trials during later stages of cultivar development. Data reported here were collected from 2014 and 2015 trials in Beltsville, MD, and describe relevant ornamental attributes (Tables 1 and 2). Compar- ative data are provided for the ornamental peppers 'Black Pearl' (Stommel and Griesbach, 2005) and 'Pepper Jack' (Stommel and Griesbach, 2008)

Plant habit for 'Christmas Lights Blue/ Red', 'Christmas Lights Blue/Orange', 'Christmas Lights Yellow/Red', and 'Christmas Lights Yellow/Orange' is compact and upright. Plants averaged $39.9-48.4 \mathrm{~cm}$ in diameter and $21.9-31.2 \mathrm{~cm}$ in height in 2014, and 58.6-70.2 $\mathrm{cm}$ in diameter and $32.5-42.8 \mathrm{~cm}$ in height in the 2015 trials. A relatively smaller plant size in 2014 occurred on nutrient poor sandy soils. Despite smaller plant size in 2014, the cultivars maintained their characteristic ornamental qualities across the trials. Plant height/diameter ratios (0.5-0.7; $75 \mathrm{~d}$ posttransplanting) were similar for the 2014 and 2015 trials. Plants of these cultivars are shorter than 'Black Pearl' and 'Pepper Jack' with height/diameter ratios less than 'Black Pearl'.

Roots of the Christmas Lights series of cultivars are fibrous and leaves are lanceolate with an apiculate tip. Leaves and stems are glabrous and glossy. Leaves are simple, entire, and symmetrical. Mature leaves averaged $5.8-7.4 \mathrm{~cm}$ in length and $2.7-3.2 \mathrm{~cm}$ in width in 2014, and 7.3-7.7 cm in length and $3.2-3.6 \mathrm{~cm}$ in width in the 2015 trials. Leaf length/width averaged 2.1-2.4 and was similar for both the 2014 and 2015 trials. Petiole length averaged $2.8-3.4 \mathrm{~cm}$ for both the trials. Leaf size was comparable with 'Pepper Jack' and smaller than 'Black Pearl' and similar in shape to both 'Pepper Jack' and 'Black Pearl'. Adaxial leaf surfaces of the Christmas Lights series cultivars are dark green (147A) (Royal Horticultural Society, 1966).

Flowers are self-compatible, hermaphroditic, pentamerous, and hypogynous. Flowers of 'Christmas Lights Blue/Red' and 'Christmas Lights Blue/Orange' are purple (81A) and have purple filaments, anthers, and styles. Flowers of 'Christmas Lights Yellow/ Red' and 'Christmas Lights Yellow/Orange' are white and have white filaments and styles; anthers are yellow with purple margins. Fruit attributes were similar for the 2014 and 2015 trials. Fruits are solitary and borne upright on $1.8-2.2 \mathrm{~cm}$ pedicels. Immature fruits of 'Christmas Lights Blue/Red' and 'Christmas Lights Blue/Orange' are violet (79A) and mature to red (45A) and orange (23A), respectively. Immature fruits of 'Christmas Lights Yellow/Red' and 'Christmas Lights Yellow/Orange' are pale yellow (4C) and mature to red (45A) and orange (23A), respectively. Fruits are conical and average 1.3-2.1 $\mathrm{cm}$ in diameter at the calyx attachment and $1.9-2.8 \mathrm{~cm}$ in length. Fruit contain two to three locules. Average fruit pericarp thickness is 1.8-2.0 $\mathrm{mm}$. The Christmas Lights cultivars and 'Pepper Jack' both produce conicalshaped fruit, but fruit of Christmas Lights cultivars are wider at the calyx attachment and shorter in length than 'Pepper Jack' fruit. 'Black Pearl' fruit are round, and unlike the Christmas Lights cultivars and 'Pepper Jack', are borne in clusters. 
Table 1. Comparative data describing plant habit and foliar and fruit morphology for the ornamental pepper (Capsicum annuum L.) cultivars comprising the following Christmas Lights cultivar series: 'Christmas Lights Blue/Red', 'Christmas Lights Blue/Orange', 'Christmas Lights Yellow/Red', and 'Christmas Lights Yellow/Orange'. Color designations for the respective cultivars denote immature fruit color (blue or yellow) and mature fruit color (red or orange). Data represent ten observations collected from the 2014 trials in Beltsville, MD.

\begin{tabular}{|c|c|c|c|c|c|}
\hline & \multirow[b]{2}{*}{ Attribute } & \multicolumn{4}{|c|}{ Cultivar } \\
\hline & & $\begin{array}{c}\text { Christmas Lights } \\
\text { Blue/Red }\end{array}$ & $\begin{array}{c}\text { Christmas Lights } \\
\text { Blue/Orange }\end{array}$ & $\begin{array}{c}\text { Christmas Lights } \\
\text { Yellow/Red }\end{array}$ & $\begin{array}{c}\text { Christmas Lights } \\
\text { Yellow/Orange }\end{array}$ \\
\hline \multirow[t]{3}{*}{$\overline{\text { Plant }}$} & Height $(\mathrm{cm})$ & $31.2 \pm 0.9^{\mathrm{z}}$ & $26.8 \pm 0.6$ & $29.1 \pm 0.9$ & $21.9 \pm 0.7$ \\
\hline & Diameter $(\mathrm{cm})$ & $44.3 \pm 2.0$ & $44.1 \pm 1.7$ & $48.4 \pm 1.8$ & $39.9 \pm 1.1$ \\
\hline & Height/diameter & $0.7 \pm 0.03$ & $0.6 \pm 0.02$ & $0.6 \pm 0.03$ & $0.6 \pm 0.02$ \\
\hline \multirow[t]{4}{*}{ Leaf } & Length $(\mathrm{cm})$ & $5.8 \pm 0.2$ & $6.2 \pm 0.2$ & $6.6 \pm 0.2$ & $7.4 \pm 0.2$ \\
\hline & Width $(\mathrm{cm})$ & $2.7 \pm 0.1$ & $2.7 \pm 0.1$ & $3.1 \pm 0.1$ & $3.2 \pm 0.1$ \\
\hline & Length/width & $2.1 \pm 0.1$ & $2.4 \pm 0.2$ & $2.2 \pm 0.1$ & $2.3 \pm 0.03$ \\
\hline & Color, $\mathrm{RHS}^{\mathrm{y}}$ \# & Green, 147A & Green, $147 \mathrm{~A}$ & Green, 147A & Green, 147A \\
\hline \multirow[t]{6}{*}{ Fruit } & Length & $2.1 \pm 0.1$ & $2.5 \pm 0.1$ & $2.8 \pm 0.1$ & $2.6 \pm 0.1$ \\
\hline & Diameter at calyx $(\mathrm{cm})$ & $1.5 \pm 0.04$ & $1.6 \pm 0.1$ & $2.1 \pm 0.1$ & $1.8 \pm 0.1$ \\
\hline & Diameter at midpoint $(\mathrm{cm})$ & $1.3 \pm 0.1$ & $1.4 \pm 0.1$ & $1.6 \pm 0.1$ & $1.5 \pm 0.1$ \\
\hline & Fruit/cluster & 1 & 1 & 1 & 1 \\
\hline & Color, RHS \# immature & Violet, 79A & Violet, 79A & Yellow, 4C & Yellow, 4C \\
\hline & Color, RHS \# mature & Red, $45 \mathrm{~A}$ & Orange, $23 \mathrm{~A}$ & Red, 45A & Orange, $23 \mathrm{~A}$ \\
\hline
\end{tabular}

${ }^{\mathrm{z}}$ Mean $\pm \mathrm{SE}$.

${ }^{\mathrm{y}} \mathrm{RHS}=$ Royal Horticultural Society.

Table 2. Comparative data describing plant habit and foliar and fruit morphology for the ornamental pepper (Capsicum annuum L.) cultivars comprising the following Christmas Lights cultivar series: 'Christmas Lights Blue/Red', 'Christmas Lights Blue/Orange', 'Christmas Lights Yellow/Red', and 'Christmas Lights Yellow/Orange'. Color designations denote pigmentation of immature and mature fruit, respectively. Data represent ten observations collected from the 2015 trials in Beltsville, MD.

\begin{tabular}{|c|c|c|c|c|c|c|c|}
\hline \multirow{2}{*}{\multicolumn{2}{|c|}{ Attribute }} & \multicolumn{6}{|c|}{ Cultivar } \\
\hline & & $\begin{array}{c}\text { Christmas Lights } \\
\text { Blue/Red }\end{array}$ & $\begin{array}{c}\text { Christmas Lights } \\
\text { Blue/Orange }\end{array}$ & $\begin{array}{c}\text { Christmas Lights } \\
\text { Yellow/Red }\end{array}$ & $\begin{array}{c}\text { Christmas Lights } \\
\text { Yellow/Orange }\end{array}$ & Black Pearl & Pepper Jack \\
\hline \multirow[t]{3}{*}{$\overline{\text { Plant }}$} & Height $(\mathrm{cm})$ & $34.0 \pm 1.5^{z}$ & $42.8 \pm 1.1$ & $39.9 \pm 1.1$ & $32.5 \pm 0.9$ & $48.5 \pm 2.4$ & $43.7 \pm 1.7$ \\
\hline & Diameter $(\mathrm{cm})$ & $62.5 \pm 1.8$ & $70.2 \pm 1.7$ & $69.1 \pm 2.9$ & $58.6 \pm 1.7$ & $61.3 \pm 1.3$ & $69.1 \pm 2.4$ \\
\hline & Height/diameter & $0.5 \pm 0.03$ & $0.6 \pm 0.03$ & $0.6 \pm 0.03$ & $0.6 \pm 0.01$ & $0.8 \pm 0.04$ & $0.60 \pm 0.02$ \\
\hline \multirow[t]{4}{*}{ Leaf } & Length $(\mathrm{cm})$ & $7.7 \pm 0.3$ & $7.4 \pm 0.5$ & $7.4 \pm 0.3$ & $7.3 \pm 0.3$ & $9.9 \pm 0.4$ & $7.2 \pm 0.3$ \\
\hline & Width $(\mathrm{cm})$ & $3.6 \pm 0.1$ & $3.2 \pm 0.1$ & $3.5 \pm 0.1$ & $3.5 \pm 0.1$ & $4.4 \pm 0.2$ & $3.1 \pm 0.1$ \\
\hline & Length/width & $2.1 \pm 0.03$ & $2.3 \pm 0.05$ & $2.1 \pm 0.03$ & $2.1 \pm 0.03$ & $2.2 \pm 0.04$ & $2.3 \pm 0.05$ \\
\hline & Color, RHS ${ }^{\mathrm{y} \#}$ & Green, 147A & Green, 147A & Green, 147A & Green, 147A & Black, 202A & Green, 132C Black, 202A \\
\hline \multirow[t]{6}{*}{ Fruit } & Length & $1.9 \pm 0.1$ & $2.3 \pm 0.1$ & $2.5 \pm 0.1$ & $2.6 \pm 0.1$ & $1.6 \pm 0.03$ & $3.5 \pm 0.07$ \\
\hline & Diameter at calyx $(\mathrm{cm})$ & $1.3 \pm 0.04$ & $1.5 \pm 0.03$ & $1.7 \pm 0.1$ & $1.6 \pm 0.04$ & $1.3 \pm 0.03$ & $1.1 \pm 0.03$ \\
\hline & Diameter at midpoint $(\mathrm{cm})$ & $1.6 \pm 0.1$ & $1.7 \pm 0.05$ & $2.0 \pm 0.04$ & $1.8 \pm 0.03$ & $1.7 \pm 0.02$ & $1.2 \pm 0.03$ \\
\hline & Fruit/cluster & 1 & 1 & 1 & 1 & $10.9 \pm 1.1$ & 1 \\
\hline & Color, RHS\# immature & Violet, 79A & Violet, 79A & Yellow, 4C & Yellow, 4C & Black, 202A & Black, 202A \\
\hline & Color, RHS\# mature & Red, $45 \mathrm{~A}$ & Orange, $23 \mathrm{~A}$ & Red, $45 \mathrm{~A}$ & Orange, $23 \mathrm{~A}$ & Red, 46A & Orange, $25 \mathrm{~A}$ \\
\hline
\end{tabular}

${ }^{\mathrm{z}}$ Mean $\pm \mathrm{SE}$.

${ }^{y}$ RHS = Royal Horticultural Society.

The Christmas Lights series of cultivars produce a flush of full-size immature fruit in $\approx 50 \mathrm{~d}$ from transplanting that mature to red or orange fruit color in $\approx 70-75 \mathrm{~d}$ after transplanting under good growing conditions (see Culture section). Additional fruit will continue to develop and ripen until frost in nonprotected environments, providing an attractive display of immature and mature fruit colors. Cultivars of the Christmas Lights series bear mature fruit $\approx 10$-days earlier than 'Pepper Jack' or 'Black Pearl'. Fruit are pungent. Scoville pungency units were not determined because these cultivars are intended for ornamental applications.

Plants of the Christmas Lights cultivar series were free of disease problems in Maryland open field trials and in pot trials in Georgia. Like most ornamental and culinary peppers, western flower thrips and green peach aphid infestations occur in greenhouse culture and require routine pest management practices (Wyenandt, 2017).

\section{Culture}

The Christmas Lights cultivar series have been trialed for use as bedding plants where their compact growth habit and brightly colored erect fruit provide an attractive ornamental display. Plants are well-suited for culture as specimen plants in outdoor beds or massed at 30- to 35-inch plant spacing. Commercial evaluations suggest that these cultivars are equally well-suited for pot culture under high light conditions. Plants are best established from transplants produced in a warm greenhouse $\left(21\right.$ to $24{ }^{\circ} \mathrm{C}$ ) where seedling emergence occurs in 10-12 d. Plants suitable for transplanting $(15-20 \mathrm{~cm}$ tall) are ready in six weeks from seeding and prefer a well-drained loam or sandy loam soil with some organic matter and a $\mathrm{pH}$ range of 6.2-6.8. When grown on nutrient poor soils, supplementary fertilization improves plant vigor. Drainage is essential to reduce the incidence of soil-borne diseases such as phytophthora root rot. Similar to culinary pepper production, ornamental peppers are a warm season crop requiring minimum daytime temperatures of 18 to $21{ }^{\circ} \mathrm{C}$ (Love, 1987). Best growth is achieved at higher temperatures up to $32{ }^{\circ} \mathrm{C}$ (Bosland, 1999). Similar to many currently available ornamental pepper cultivars (Coon et al., 2017), the Christmas Lights cultivars do not require pinching or growth regulator treatments to maintain their growth habit.

\section{Availability}

Voucher seed samples of these releases will be deposited in the USDA, National Plant Germplasm System, where they will be available for research purposes, including development and commercialization of new cultivars. It is requested that appropriate recognition be made if this germplasm contributes to the development of a new breeding line or cultivar. A limited quantity of seed is available for distribution to research personnel on written request to John R. Stommel, USDA, ARS, GIFVL, BARC-West, B-010A, 
10300 Baltimore Ave., Beltsville, MD 20705; E-mail: john.stommel@ars.usda.gov.

\section{Literature Cited}

American Horticultural Society. 1997. Plant heatzone map. Amer. Hort. Soc., Alexandria, VA.

Bosland, P.W. 1999. Encyclopedia of chiles, p. 1721. In: B. Hanson (ed.). Chile peppers: Brooklyn botanical garden handbook series. Brooklyn, NY.

Coon, D., D.W. Barchenger, and P.W. Bosland. 2017. Evaluation of dwarf ornamental chile pepper cultivars for commercial greenhouse production. HortTechnology 27:128-131.

Harthun, E. 1991. Ornamental peppers and Christmas cherry, p. 670-672. In: V. Ball (ed.). Ball red book. 15th ed. Geo. J. Ball Publishing, Chicago, IL.
Love, J.W. 1987. Commercial production of potted ornamental peppers. Horticulture Information Leaflet No. 548, North Carolina Agricultural Extension Service, North Carolina State University, Raleigh, NC.

Pickersgill, B. 1969a. The archaeological record of chili peppers (Capsicum spp.) and the sequence of plant domestication in Peru. Amer. Antiq. 34:54-61.

Pickersgill, B. 1969b. The domestication of chili peppers, p. 443-450. In: P.J. Ucko and G.W. Dimbleby (eds.). The domestication and exploitation of plants and animals. Duckworth, London, UK.

Royal Horticultural Society. 1966. Royal Horticultural Society colour chart. Royal Hort. Soc., London, UK.

Stommel, J.R. and P.W. Bosland. 2005. Pepper, Ornamental, Capsicum annuum, p. 561-599.
In: N.O. Anderson (ed.). Flower breeding and genetics: Issues, challenges and opportunities for the 21 st century. Springer, Dordrecht, The Netherlands.

Stommel, J.R. and R.G. Griesbach. 1993. New ornamental Capsicum germplasm: Lines 90C40, 90C44, and 90C53. HortScience 28:858-859.

Stommel, J.R. and R.G. Griesbach. 2005. Capsicum annuиm L. 'Black Pearl'. HortScience 40:1571-1573.

Stommel, J.R. and R.G. Griesbach. 2008. Capsicum annuum L. Lil' Pumpkin ${ }^{\mathrm{TM}}$ and Pepper Jack $^{\mathrm{TM}}$. HortScience 43:935-938.

Wyenandt, A. 2017. Peppers, p. F117-F131.20162017 Mid-Atlantic commercial vegetable production recommendations. Publication No. E001, Rutgers NJAES Cooperative Extension. 28 Sept. 2017. <http://njaes.rutgers.edu/pubs/ publication.asp?pid=E001>. 